\title{
Contributors
}

\section{Mario Calderini}

Professor of Economics and Management, Politecnico di Torino, Italy

\section{Paola Garrone}

Professor of Economics, Politecnico di Milano, Italy

\section{Giancarlo Giudici}

Research Fellow, Department of Engineering, Università di Bergamo, Italy

\section{Federico Munari}

Research Fellow, Department of Management, Università di Bologna, Italy

\section{Raffaele Oriani}

Research Fellow, Department of Management, Università di Bologna, Italy

\section{Stefano Paleari}

Professor of Management and Finance, Università di Bergamo, Italy

\section{Giuseppe Scellato}

Research Fellow, Department of Production Economics, Politecnico di Torino, Italy

\section{Maurizio Sobrero}

Professor of Management, Università di Bologna, Italy 


\section{This Page Intentionally Left Blank}

